\title{
Studies on Pollution due to discharge of effluent from Pharmaceutical Industries of Dombivali Industrial Belt of Mumbai, India
}

\author{
P. U. Singare ${ }^{1, *}$, S. S. Dhabarde ${ }^{2,3}$ \\ ${ }^{1}$ Department of Chemistry, Bhavan's College, Munshi Nagar, Andheri (West), Mumbai, \\ Maharashtra 400058, India \\ ${ }^{2}$ Department of Chemistry, K.V. Pendharkar College, Dombivali (East), Dist. Thane, \\ Maharashtra 421201, India \\ ${ }^{3}$ Department of Chemistry, Pacific University of Higher Education \& Research University, \\ Udaipur, Rajasthan, India \\ *E-mail address: pravinsingare@gmail.com
}

\begin{abstract}
The paper deals with monitoring of pollution arising due to pharmaceutical based industries located along the Dombivali industrial belt of Mumbai, India. The study was carried for the period of one year from June, 2012 to May, 2013 to study the level of toxic heavy metals and the physicochemical properties of waste water effluents discharged from the above industries. The concentration level of majority of toxic heavy metals like $\mathrm{Cu}, \mathrm{Cr}, \mathrm{Pb}, \mathrm{Fe}$ and $\mathrm{Zn}$ were found to be maximum of $14.06,0.57,0.42,18.93$ and $3.31 \mathrm{ppm}$ respectively in the month of February, while Ni concentration was found to be maximum of $0.43 \mathrm{ppm}$ in the month of June. The $\mathrm{pH}$ and BOD values were reported to be maximum of 12.54 and $546 \mathrm{ppm}$ respectively in the month of October. The conductivity and total solid content was found to be maximum of $27400 \mu \mathrm{mhos} / \mathrm{cm}$ and $9401 \mathrm{ppm}$ respectively in the month of June. The cyanide content was maximum of $0.13 \mathrm{ppm}$ in the month of April. The alkalinity, hardness, salinity, chloride, phosphate and COD content was reported maximum of 852, 694, 10.36, 4821, 46.32 and $1271 \mathrm{ppm}$ respectively in the month of February. The DO content was found to be minimum of $3.00 \mathrm{ppm}$ in the month of February. It was observed that the level of many of these toxic heavy metals except $\mathrm{Zn}$ and various physico-chemical parameters were above the tolerable limit set for inland surface water. From the results of the present investigation it seems that the time has come to move towards ecosystem specific discharge standards to maintain the health and productivity of natural resources on which the majority of Indians are dependent.
\end{abstract}

Keywords: industrial pollution; waste water effluent; physico-chemical analysis; toxic heavy metals; pharmaceutical industries; Dombivali industrial belt; Mumbai

\section{INTRODUCTION}

Over the last decade, more than 100 different drugs have been found as environmental contaminants in effluents of sewage treatment plants, surface water, sediments, sludge, soils, groundwater and even drinking water sources [1-7]. The widespread detection of pharmaceuticals in environmental samples as a result of improved analytical capabilities and focused field surveys has led to concern over the potential risks associated with releases of pharmaceuticals into the environment. This concern has been driven by surface water 
sampling programs in the US, Europe and elsewhere that have all shown the presence of many different classes of pharmaceuticals. The high polarity and low volatility of most pharmaceuticals means that they are likely to be transported to and by the water compartment. In recent years it has been clear that pharmaceuticals released into the environment are an important group of environmental pollutants [8]. Many reports have been published that proves the widespread occurrence of these pollutants in waste water, ground water and surface water [6,9-13]. Pharmaceuticals that are made to interact with living organisms can also have acute effects on fauna and flora, but due to low concentrations this will not be the biggest concern [14]. Synthetic and semisynthetic pharmaceuticals and pesticides are known to pollute the aquatic, terrestrial, and atmospheric environment alike, and they usually find their way into the drinking water as a dilute cocktail of varied drugs in varied concentrations. About 26 metric tons of pharmaceutical waste is disposed annually down the drain, and another 26 tons are disposed annually with municipal solid waste in landfills in North America alone [15]. North American [16], Canadian [17], Japanese [18], Korean [19], and across the Europe, waterways [20] contain traces (in nanograms/L to micrograms/L) of antibiotics, painkillers, hormones, tranquilizers, anti-inflammatory, chemotherapeutic, antiepileptic and hypolipidemic drugs [3,7,9,21,22].

When such wastewater is used for irrigation pharmaceuticals may also be released to soils [23]. Use and misuse of pharmaceuticals, by man is causing havoc with nature, as they persist as such or as their toxic metabolites. These pollutants bioaccumulate in environment, and they ultimately reach man through various means. They are hazardous because of potential toxicity, mutagenicity, carcinogenicity, and genotoxicity [24]. Considering the environmental impact of pollution arising from pharmaceutical based industries at global level, in the present investigation attempts was made to carry out the extensive monitoring of effluents released from such industries located in Dombivali MIDC industrial belt which is considered to be one of the most polluted industrial belts of Mumbai.

\section{EXPERIMENTAL}

\section{1. Study area}

The Dombivali industrial area was established by Maharashtra Industrial Development Corporation (M.I.D.C) in 1964. The industrial belt occupies an area of about 347.88 hector, is located in south of Ulhas River and about $45.00 \mathrm{~km}$ from Mumbai international airport.

There are about 30 highly polluting small/ medium/ large scale chemical industries located in this industrial belt. Quantity of industrial effluent generated in the industrial area is about 14 MLD, which is finally discharged into the creek through open drainages which was passing through residential area [25].

\section{2. Climatic condition}

Dombivali enjoys a tropical climate with mean annual temperature of $24.3{ }^{\circ} \mathrm{C}(\mathrm{min})$ to $32.9^{\circ} \mathrm{C}(\max )$. The hottest and driest part of the year is April-May, when temperature rises to $38.0{ }^{\circ} \mathrm{C}$. The humidity is usually in the range of 58 to $84 \%$ and sea breeze in the evening hours is a blessing to combat the high temperature and humidity during summer months. The average southwest monsoon rainfall is in the range of $1850 \mathrm{~mm}$ to $2000 \mathrm{~mm}$. The average annual rainfall in the region is the range from 1286 to $1233 \mathrm{~mm}$ [25]. 


\section{3. Requirements}

All the chemicals and reagent used for analysis were of analytical reagent grade. The glasswares used in the analysis were washed with distilled de-ionized water; the pipettes and burette were rinsed with the experimental solution before final use.

\section{4. Industrial Effluent Sampling and Preservation}

The industrial waste water effluent samples were collected randomly twice in a month in morning, afternoon and evening session from three representative pharmaceutical manufacturing units of Dombivali industrial belt of Mumbai. The samples were collected every month from June, 2012 to May, 2013. Polythene bottles of 2.5 L and 2.0 L were used to collect the grab water samples (number of samples collected, $n=20$ ). The bottles were thoroughly cleaned with hydrochloric acid, washed with tape water to render free of acid, washed with distilled water twice, again rinsed with the water sample to be collected and then filled up the bottle with the sample leaving only a small air gap at the top. The sample bottles were stoppard and sealed with paraffin wax.

\section{5. Physico-chemical Study}

The samples were collected were analyzed for $\mathrm{pH}$, conductivity, alkalinity, hardness, salinity, chloride, cyanide, phosphate content, Total Dissolved Solids (T.D.S), Total Suspended Solids (T.S.S), Total Solids (T.S), Dissolved Oxygen (D.O), Bio-chemical Oxygen Demand (B.O.D) and Chemical Oxygen Demand (C.O.D) values. The techniques and methods followed for collection, preservation, analysis and interpretation are those given by Rainwater and Thatcher [26], Brown et al. [27], I.C.M.R [28], Hem [29] and A.P.H.A [30].

\section{6. Heavy Metal Analysis by AAS Technique}

Water samples $(500 \mathrm{~mL})$ were filtered using Whatman No. $41(0.45 \mu \mathrm{m}$ pore size $)$ filter paper for estimation of dissolved metal content. Filtrate $(500 \mathrm{~mL})$ was preserved with $2 \mathrm{~mL}$ nitric acid to prevent the precipitation of metals. The samples were concentrated on a water bath depending on the suspected level of the metals [31].The analysis for the majority of the trace metals like copper $(\mathrm{Cu})$, nickel $(\mathrm{Ni})$, chromium $(\mathrm{Cr})$, lead $(\mathrm{Pb})$, iron $(\mathrm{Fe})$ and zinc $(\mathrm{Zn})$ was done by Perkin Elmer ASS-280 Flame Atomic Absorption Spectrophotometer.

The calibration curves were prepared separately for all the metals by running different concentrations of standard solutions. A reagent blank sample was run throughout the method, and the blank readings were subtracted from the samples to correct for reagent impurities and other sources of errors from the environment. Average values of three replicates were taken for each determination.

\section{RESULTS AND DISCUSSION}

The experimentally measured pollution data on heavy metal content and physicochemical properties of industrial waste water effluents released from pharmaceutical based industries located along the Dombivali industrial belt of Mumbai is presented in Tables 1 and 2.

Trace elements are those elements which are present in relatively low concentration of less than few ppm. Among the special group of trace elements are the heavy metals which are having the potential to create health hazards among humans, plants and other aquatic biological life. Under the group of heavy metals are $\mathrm{Cr}, \mathrm{Ni}, \mathrm{Zn}, \mathrm{Cu}, \mathrm{Pb}$ and $\mathrm{Fe}$. 
Table 1. Physico-chemical properties of the effluents released from Pharmaceutical industries located along Dombivali Industrial Belt of Mumbai, India.

\begin{tabular}{|c|c|c|c|c|c|c|c|c|c|c|c|c|}
\hline 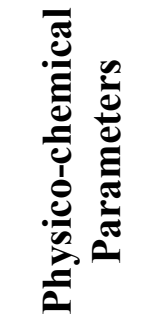 & 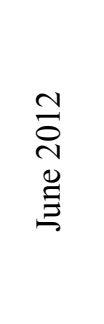 & $\begin{array}{l}\stackrel{N}{\Xi} \\
\stackrel{N}{1} \\
\stackrel{2}{\Xi}\end{array}$ & 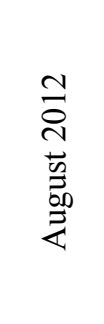 & 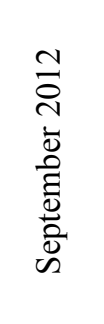 & 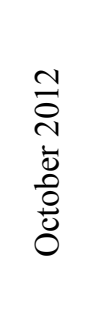 & 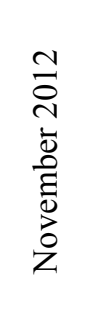 & 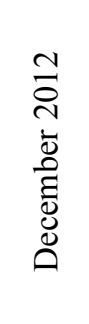 & 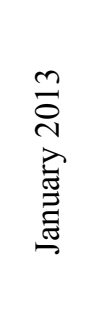 & 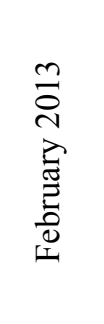 & 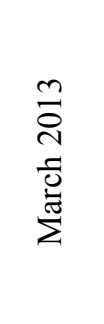 & 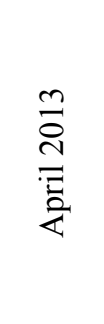 & $\begin{array}{l}\frac{m}{\sigma} \\
\stackrel{N}{2} \\
\stackrel{\vec{\Xi}}{\Sigma}\end{array}$ \\
\hline $\mathrm{pH}$ & 9.08 & 10.21 & 9.00 & 11.33 & 12.54 & 12.50 & 12.01 & 11.32 & 7.80 & 8.25 & 9.03 & 7.96 \\
\hline $\begin{array}{l}\text { Conductivity } \\
(\mu \mathrm{mhos} / \mathrm{cm})\end{array}$ & 27400 & 25630 & 20500 & 15480 & 1343 & 1445 & 1603 & 1987 & 27000 & 27200 & 26078 & 25760 \\
\hline $\begin{array}{c}\text { Alkalinity } \\
(\mathrm{ppm})\end{array}$ & 276 & 431 & 201 & 191 & 154 & 234 & 465 & 683 & 852 & 650 & 657 & 439 \\
\hline $\begin{array}{c}\text { Hardness } \\
(\mathrm{ppm})\end{array}$ & 248 & 145 & 126 & 214 & 88 & 150 & 345 & 569 & 694 & 654 & 362 & 376 \\
\hline $\begin{array}{l}\text { Salinity } \\
(\mathrm{ppm})\end{array}$ & 4.80 & 4.64 & 4.89 & 4.39 & 4.36 & 6.56 & 7.70 & 9.43 & 10.36 & 10.26 & 8.80 & 9.54 \\
\hline $\mathrm{Cl}^{-}(\mathrm{ppm})$ & 2049 & 2026 & 1572 & 1295 & 616 & 775 & 1245 & 1786 & 4821 & 3243 & 3037 & 2025 \\
\hline $\mathrm{CN}^{-}(\mathrm{ppm})$ & 0.02 & 0.04 & 0.03 & 0.05 & 0.05 & 0.08 & 0.09 & 0.06 & 0.10 & 0.09 & 0.13 & 0.10 \\
\hline $\begin{array}{l}\text { Phosphates } \\
\text { (ppm) }\end{array}$ & 10.23 & 13.20 & 15.54 & 12.25 & 12.23 & 15.25 & 20.13 & 25.67 & 46.32 & 43.30 & 40.24 & 42.67 \\
\hline TDS (ppm) & 8741 & 6500 & 3545 & 1783 & 900 & 1100 & 1432 & 1564 & 1611 & 2312 & 3033 & 4436 \\
\hline TSS (ppm) & 660 & 435 & 358 & 257 & 200 & 400 & 879 & 2570 & 2980 & 2679 & 1450 & 953 \\
\hline TS (ppm) & 9401 & 6935 & 3903 & 2040 & 1100 & 1500 & 2311 & 4134 & 4591 & 4991 & 4483 & 5389 \\
\hline D.O (ppm) & 3.50 & 4.50 & 3.70 & 4.00 & 4.40 & 4.60 & 4.30 & 4.00 & 3.00 & 4.70 & 3.90 & 4.50 \\
\hline $\begin{array}{l}\text { B.O.D } \\
(\mathrm{ppm})\end{array}$ & 106 & 137 & 370 & 459 & 546 & 530 & 524 & 510 & 508 & 348 & 215 & 270 \\
\hline $\begin{array}{l}\text { C.O.D } \\
(\mathrm{ppm})\end{array}$ & 834 & 549 & 396 & 375 & 363 & 643 & 753 & 950 & 1271 & 971 & 1045 & 894 \\
\hline
\end{tabular}

They are classified under the group of heavy metals because in metallic form they have the densities higher than $4 \mathrm{~g} / \mathrm{cm}^{3}$. The $\mathrm{Cu}$ content was found to vary in the range of $0.17 \mathrm{ppm}$ in the month of June to $14.06 \mathrm{ppm}$ in the month of February. The values reported were above the permissible limit of $0.05 \mathrm{ppm}$ set by $W . H . O$ and $1.0 \mathrm{ppm}$ as per the USPH standards. The $\mathrm{Ni}$ content was found to be minimum of $0.21 \mathrm{ppm}$ in the month of July to maximum of 0.43 ppm in the month of June. The overall experimental observed $N i$ concentration was above the maximum limit of $0.1 \mathrm{ppm}$ set by W.H.O.

The $\mathrm{Cr}$ content was found to vary in the range of $0.40 \mathrm{ppm}$ in the month of October to $0.57 \mathrm{ppm}$ in the month of February. The $\mathrm{Cr}$ values reported were above the maximum permissible limit of $0.05 \mathrm{ppm}$ set by W.H.O [32]. The Pb content was found to vary in the range of $0.31 \mathrm{ppm}$ in the month of September to $0.42 \mathrm{ppm}$ in the month of February. The values of $\mathrm{Pb}$ were extremely above the general standard limit of $0.1 \mathrm{ppm}$ lead set for effluents discharge in inland surface water [33]. The Fe content was found to vary in the range of 0.29 
ppm in the month of June to $18.93 \mathrm{ppm}$ in the month of February. The reported level of $\mathrm{Fe}$ from the month of November to May were very much above the permissible limit of $3.0 \mathrm{ppm}$ iron set for effluents discharge in inland surface water [33]. The Zn content was found to vary in the range of $0.76 \mathrm{ppm}$ in the month of October to $3.31 \mathrm{ppm}$ in the month of February.

Table 2. Heavy Metal content in the effluents released from Pharmaceutical industries located along Dombivali Industrial Belt of Mumbai, India.

\begin{tabular}{|c|c|c|c|c|c|c|c|c|c|c|c|c|}
\hline 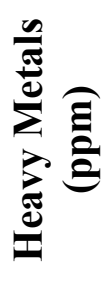 & 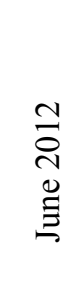 & $\begin{array}{l}\stackrel{\sim}{\vdots} \\
\stackrel{N}{2} \\
\stackrel{2}{\Xi}\end{array}$ & 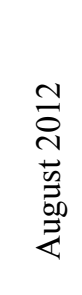 & 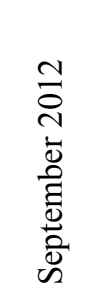 & 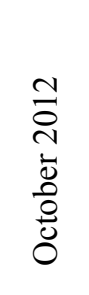 & 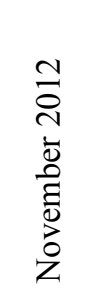 & 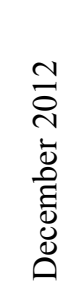 & 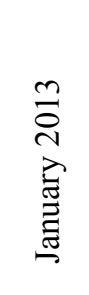 & 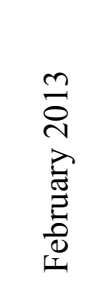 & 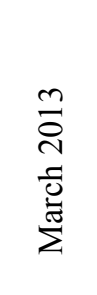 & 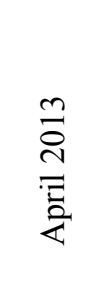 & $\begin{array}{l}\stackrel{0}{\vdots} \\
\stackrel{\sim}{2} \\
\stackrel{\Xi}{\Sigma}\end{array}$ \\
\hline $\mathrm{Cu}$ & 0.17 & 0.29 & 0.23 & 0.19 & 0.79 & 0.78 & 0.75 & 0.80 & 14.06 & 12.40 & 10.30 & 11.50 \\
\hline $\mathrm{Ni}$ & 0.43 & 0.21 & 0.35 & 0.33 & 0.35 & 0.30 & 0.25 & 0.36 & 0.31 & 0.34 & 0.42 & 0.41 \\
\hline $\mathrm{Cr}$ & 0.48 & 0.49 & 0.56 & 0.53 & 0.40 & 0.49 & 0.54 & 0.47 & 0.57 & 0.49 & 0.53 & 0.55 \\
\hline $\mathrm{Pb}$ & 0.33 & 0.39 & 0.34 & 0.31 & 0.33 & 0.35 & 0.37 & 0.41 & 0.42 & 0.40 & 0.38 & 0.32 \\
\hline $\mathrm{Fe}$ & 0.29 & 0.57 & 1.83 & 1.79 & 2.51 & 4.65 & 6.36 & 9.80 & 18.93 & 15.9 & 12.32 & 17.26 \\
\hline $\mathrm{Zn}$ & 1.28 & 1.00 & 1.20 & 1.13 & 0.76 & 0.89 & 0.95 & 1.50 & 3.31 & 2.38 & 2.00 & 1.05 \\
\hline
\end{tabular}

The reported level of $Z n$ in the effluent samples collected for different months were within the general standard limit of $5.0 \mathrm{ppm} \mathrm{Zn}$ set for effluents discharge in inland surface water [33]. In any environmental monitoring study related to pollution of surface water, physico-chemical parameters gives valuable information regarding the pollution load. It is found that most of the industries in India are located near the water bodies because of their extensive requirement of water for various industrial activities.

The industrial waste water is generally discharged in drainages which finally enter the nearby water bodies creating extensive pollution creating threat to the aquatic life and health of surrounding human population. The most common physico-chemical parameters are $\mathrm{pH}$, conductivity, hardness, alkalinity, suspended and dissolved solids, BOD, COD and DO. These parameters generally decide the extent of pollution and help in planning the waste water treatment technology which is to be adopted. In the present investigation it was observed that the $\mathrm{pH}$ of collected effluents was found to vary in the range of 7.80 in the month of February to maximum of 12.54 in the month of October. During major assessment period, the $\mathrm{pH}$ values recorded were above the permissible $\mathrm{pH}$ range of 5.5 to 9.0 as set for inland surface water subjected to pollution load [33-43].

The conductivity values recorded was found to be minimum of $1343 \mu \mathrm{mhos} / \mathrm{cm}$ in the month of October to maximum of $27400 \mu \mathrm{mhos} / \mathrm{cm}$ in the month of June. The majority of physic-chemical parameters like alkalinity, hardness, salinity, and chloride content were found to be minimum of $154,88,4.36,616 \mathrm{ppm}$ respectively in the month of October and 
maximum of $852,694,10.36$ and 4821 ppm respectively in the month of February. The $\mathrm{CN}^{-}$ content was found to vary in the range of $0.02 \mathrm{ppm}$ in the month of June to maximum of 0.13 ppm in the month of April.

The phosphate content in the effluent samples was found to be minimum of $10.23 \mathrm{ppm}$ in the month of June to maximum of $46.32 \mathrm{ppm}$ in the month of February. The total solid (TS) content was found to vary in the range of $1100 \mathrm{ppm}$ in October to maximum of 9401 ppm in the month of June. The DO content was in the range of $3.00 \mathrm{ppm}$ which was minimum in the month of February to $4.70 \mathrm{ppm}$ which was maximum in in the month of March. The minimum BOD and COD content was found to be $106 \mathrm{ppm}$ and $363 \mathrm{ppm}$ in the month of June and October respectively, while the maximum values reported were $546 \mathrm{ppm}$ and $1271 \mathrm{ppm}$ in the month of October and February respectively.

\section{CONCLUSION}

Around the world as countries are struggling to arrive at an effective regulatory regime to control the discharge of industrial effluents into their ecosystems, Indian economy holds a double edged sword of economic growth and ecosystem collapse. As India progresses towards strict regulation of industrial effluents to control water pollution, greater efforts are required to reduce the risk to public health as colourless and odourless toxic pollutants are released into the ecosystems. Hence there is a need that each industry should treat their effluents, in accordance with the legal requirements, before discharging these into the streams otherwise 'Polluter pays' principle should be implemented.

The current regulatory system in India for control of industrial discharges needs a complete improvement in terms of standards setting, monitoring and enforcement. The monitoring system for water quality needs to be strengthened both in terms of parameters monitored, water resources coverage and timely reporting to public domain.

These steps are important in order to avoid irreparable ecological harm in the long term well masked by short term economic prosperity due to extensive industrial growth.

\section{References}

[1] Braga O., Smythe G. A., Shafer A. I., Feitz A. J., Chemosphere 61(6) (2005) 827-833.

[2] Golet E. M., Strehler A., Alder A. C., Giger W. (2002b), Anal. Chem. 64 (21) 92002) 5455-5462.

[3] Hirsch R., Ternes T., Haberer K., Kratz K-L., Sci Tot Environ 225 (1999) 109-118.

[4] Hilton M. J, Thomas K. V., J. Chromat. A 1015 (2003) 129-141.

[5] Metcalfe C., Miao X-S., Koenig B. G., Struger J., Environ Toxicol. Chem. 22 (2003) 2881-2889.

[6] Stackelberg P. E., Furlong E. T., Meyer M. T., Zaugg S. D., Henderson A. K., Reissman D. B., Sci. Total Environ. 329 (2004) 99-113.

[7] Ternes T., Water Res. 32 (1998) 3245-3260.

[8] Jorgensen S. E., Halling-Sorensen B., Chemosphere 40(7) (2000) 691-699.

[9] Heberer T., Toxicol Lett 131(1-2) (2002) 5-17. 
[10] Hernando M. D., Petrovic M., Fernandez-Alba A. R., Barcelo D., J Chromatogr A 1046(1-2) (2004) 133-140.

[11] Cahill J. D., Furlong E. T., Burkhardt M. R., Kolpin D., Anderson L. G., J Chromatogr A 1041(1-2) (2004) 171-180.

[12] Debska J., Kot-Wasik A., Namiesnik J., Crit. Rev. Anal. Chem. 34(1) (2004) 51-67.

[13] Gomez M. J., Petrovic M., Fernandez-Alba A. R., Barcelo D., J. Chromatogr. A $1114(2)$ (2006) 224-233.

[14] Jones A. H., Voulvoulis N., Lester J. N., Crit. Rev. Toxicol. 34(4) (2004) 335-350.

[15] S. M. Gualtero, "Pollution Prevention Measures for Unwanted Pharmaceuticals. Industrial Ecology," 2005.

http://www.seas.columbia.edu/earth/wtert/sofos/Gualtero_IETerm_.pdf.

[16] D. W. Kolpin, E. T. Furlong, M. T. Meyer et al., Environmental Science and Technology 36(6) (2002) 1202-1211.

[17] NWRI Scientific Assessment Report Series No. 8, Pharmaceuticals and Personal Care Products in the Canadian Environment: Research and Policy Directions, 2002.

[18] Y. Kobayashi, M. Yasojima, K. Komori, Y. Suzuki, and H. Tanaka, "Removal characteristics of human antibiotics during wastewater treatment in Japan," Water Practice \& Technology 1(3) (2006).

[19] Y. J. Lee, S. E. Lee, D. S. Lee, Y. H. Kim, Environmental Toxicology and Pharmacology 26(2) (2008) 216-221.

[20] C. Carlsson, A. K. Johnsson, G. Alvan, K. Bergman, T. Kuhler, Science of Total Environment 364(1-3) (2006) 67-87.

[21] ERAVMIS, 2009, http://www.silsoe.cranfield.ac.uk/ecochemistry/eravmis/.

[22] O. A. Jones, J. N. Lester, N. Voulvoulis, Trends in Biotechnology 23(4) (2005) 163-167.

[23] Ternes T., Bonerz M., Herrmann N., Teiser B., Andersen H. R., Chemosphere 66 (2007) 894-904.

[24] G. K. Randhawa, J. S. Kullar, Bioremediation of Pharmaceuticals, Pesticides and Petrochemicals with Gomeya/Cow Dung, ISRN Pharmacology Volume 2011 (2011), Article ID 362459, 7 pages, doi:10.5402/2011/362459.

[25] Action Plan for Industrial Cluster "Dombivali", Maharashtra Pollution Control Board, November 2010. http://www.mpcb.gov.in

[26] Rainwater F. H., Thatcher L. L., U.S. Geol. Surv. Water Supply Papers 1454 (1960) $1-301$.

[27] E. Brown, M. W. Skougstad, M. J. Fishman, 'Methods for collection and analysis of Water samples for dissolved minerals and gases', Techniques of Water Resources Investigations of the U.S. Geological Survey, Vol. 160, Book 5, Chapter A1 (1970).

[28] Indian Council of Medical Research (ICMR) Manual of Standards of Quality for Drinking Water Supplies, (1975).

[29] J. D. Hem, 'Study and Interpretation of Chemical Characteristics of Natural Water', 3rd ed., U.S. Geological Survey, Washington (1985). 
[30] American Public Health Association (APHA) Standard Methods for Estimation of Water and Wastewater, 19th ed., American Water Works Association, Water Environment Federation, Washington, (1995).

[31] Chen M., Ma L. Q., Soil Science Society of American Journal 65(2) (2001) 491-499.

[32] A. K. De, Environmental Chemistry, pp. 232-272, 4th ed., New Age International (P) Ltd., New Delhi, India (2002).

[33] The Environment (Protection) Rules (1986) Available at http://www.cpcb.nic.in/GeneralStandards.pdf (assessed on November 2011).

[34] P. Daniszewski, International Letters of Chemistry, Physics and Astronomy 4 (2012) 112-118.

[35] E. Cyrania, P. Daniszewski, B. Draszawka-Bołzan, International Letters of Chemistry, Physics and Astronomy 5 (2012) 96-103.

[36] E. Cyraniak, P. Daniszewski, B. Draszawka-Bołzan, International Letters of Chemistry, Physics and Astronomy 5 (2012) 88-95.

[37] P. Daniszewski, R. Konieczny, International Letters of Chemistry, Physics and Astronomy 4 (2013) 91-97.

[38] P. Daniszewski, R. Konieczny, International Letters of Chemistry, Physics and Astronomy 4 (2013) 98-104.

[39] P. U. Singare, M. S. Talpade, D. V. Dagli, V. G. Bhawe, International Letters of Chemistry, Physics and Astronomy 8(2) (2013) 94-104

[40] P. U. Singare, M. S. Talpade, D. V. Dagli, V. G. Bhawe, International Letters of Chemistry, Physics and Astronomy 8(2) (2013) 105-112

[41] P. Daniszewski, International Letters of Chemistry, Physics and Astronomy 8(3) (2013) 269-278.

[42] P. Daniszewski, International Letters of Chemistry, Physics and Astronomy 8(3) (2013) 279-287.

[43] P. Daniszewski, International Letters of Chemistry, Physics and Astronomy 10(2) (2013) 218-226. 